\title{
Dominik Buttler
}

ORCID: 0000-0001-9836-1047

Poznan University of Economics and Business ${ }^{1}$

\section{Between fun and obligation. The motivations of volunteers in Poland}

\begin{abstract}
The aim of this paper is to facilitate understanding of the motivations of volunteers working in Poland ${ }^{2}$. In the theoretical framework of the analysis we have applied the so-called functional approach, which recognizes six types of volunteer motivations: social, protective, enhancement, career, understanding and value-expressive. The thematic analysis of in-depth interviews with 26 volunteers addressed three objectives. First, we investigated how motivations of volunteers in Poland corresponded to the functional typology, then sought to identify distinct aspects of particular functions, and finally, tried to find new types of volunteer motivations. In the analysed interviews we found references to all six types of volunteering motives. We also identified new types of motivation (social integration and utilitarian) as well as aspects of the existing functions, which had not been recognized in the original theoretical framework.
\end{abstract}

Key words: non-profit sector, volunteer motivations, unpaid work

1 Correspondence: Katedra Pracy i Polityki Społecznej, Uniwersytet Ekonomiczny w Poznaniu, al. Niepodległości 10, 61-875 Poznań, Polska; author's email address: d.buttler@ue.poznan.pl

2 The study presented in the article was financially supported through the National Science Centre (Narodowe Centrum Nauki) grant 2013/11/D/HS4/03874. 


\section{Introduction}

The most prevalent research trend concerning motivations of volunteers (i.e. individuals freely giving time and labour for community service) employs a functional approach, which goes back to studies by Katz (1960) as well as by Smith, Bruner and White (1956). Primarily, it was used to comprehend the mechanism of attitude formation. A few decades later the functional approach was applied in the analysis of volunteer motivation (see Clary \& Snyder, 1991; Clary et al., 1996; Clary et al., 1998).

The most common motivation typology for social engagement within the functional approach recognises six groups of needs fulfilled by social activity, i.e. six functions of volunteer work: value-expressive (engagement as a way to manifest values significant for a person), career (gaining professional experience), understanding (gaining knowledge about the world and about oneself), social (reflecting the desire to act like significant others or comply with their expectations), enhancement (engagement as a way of improving psychological development and self-esteem), and protective (involvement as a mean of dealing with your own problems or to protect yourself from negative feelings about oneself). These functions are usually identified quantitively using the Volunteer Function Inventory (VFI) (Clary et al., 1998), which has become the most widely used questionnaire assessing volunteer motivations. A recent meta-analysis identified 147 studies using VFI in the period 1998-2014. The vast majority of analysed research considered the context of developed Western societies with a notable exception of China (Chacón et al., 2017). Studies from other countries, including Central and Eastern European (CEE) states, are considerably underrepresented. Moreover, most analyses focus on the application of the VFI and its statistical properties (e.g. reliability, sensitivity) and not on its elaboration. The analyses aiming to identify new volunteer functions or reject the existing ones are rare (Esmond \& Dunlop, 2004; Law et al., 2011; Hochstetler, 2013). Meanwhile, the main message of the VFI authors underlines diversity of motivations. Clary and others do not claim that their list is complete and encourage further research (Clary et al., 1998, p. 1528).

The aim of this paper is to provide understanding of the variety of volunteers' motivations within the functional framework based on the qualitative analysis of in-depth interviews with volunteers working in Poland. In particular, three research goals have been formulated. First, we investigate how motivations of volunteers in Poland correspond to the functional typology (Do the volunteers demonstrate all six types of motivations?). Then we describe various aspects of particular functions (Are there any important features of the existing volunteer functions that have not been characterized in the VFI questionnaire?). Finally, we seek to identify new types of volunteer motivations.

The reminder of this paper is structured as follows. First, we present the concept of a motivation defined in the functional framework and contrast it with related terms used in (mainly psychological) research on determinants of volunteering. Next we describe the empirical strategy, i.e. the research method and qualitative data. The third part presents results of the qualitative analysis with respect to all six functions identified in the VFI 
questionnaire. The fourth section discusses new functions, which have emerged in the analysis. The final section presents our conclusions.

\section{The concept of motivation in the functional framework}

In the empirical part of the paper we will seek to identify various types of volunteer motivations, therefore it is important to distinguish them from related concepts. The functional framework does not provide any precise criteria; however, one feature of the volunteer motivation concept is of central importance and concerns 'the agentic pursuit of ends and goals important to the individual' (Clary et al., 1998, p. 1528). Hence, the motivation to volunteer is always associated with the desire to satisfy certain needs.

A functional approach to volunteer motivations makes very clear references to functionalist theorizing in the domain of attitudes. Next to the value-expressive function addressed in both theories, Clary et al. (1998) distinguished the career and understanding types of motivations corresponding to utilitarian and knowledge functions of attitudes respectively. The original ego-defensive function was broken down into enhancement and protective volunteer motives promoting and defending self-esteem respectively. The social function of volunteering was derived from the social adjustive function of attitudes identified by Smith et al. (1956).

In the literature there is no consensus whether motivations can be treated as individual dispositions. The latter term is defined as a relatively enduring feature of an individual encompassing 'psychological structures and processes that have the potential to cause behavior'. Although dispositions are not context-independent, they 'unfold in subsets of individuals in similar ways, in similar contexts' (both quotes, Penner \& Orom, 2010, p. 57). Such a characteristic poorly describes the concept of the motivation. The central assumption of the functional framework is that the same actions may reflect different underlying motives. Moreover, since volunteer functions aim at satisfying particular needs, they are much more context-dependent. On the other hand, according to Rioux and Penner (2001) some motivations are relatively stable over time and are closely related to personality traits. It concerns the value-expressive function ${ }^{3}$ in particular. In order to understand the concept of motivation better, in the remaining part of this section we will contrast it with related terms used in the psychological literature to describe the voluntary engagement. We will consider the following concepts in particular: attitudes, personality traits, social support, obligations and values.

3 Rioux and Penner (2001) tested the citizenship motives scale developed within the functional theoretical framework. Among three types of motivations, they distinguished the 'prosocial values' (a construct very similar to the value-expressive function of volunteering) and the 'organizational concern' (related to the understanding function). The strong correlation between the former dimension and the prosocial personality convinced the authors to classify it as a person's disposition. On the contrary, the 'organizational concern' was considered much more context-specific (Rioux \& Penner 2001, p. 1313). 


\section{Volunteer motivations and attitudes}

In the theory of planned behaviour (TPB) (Ajzen, 2011), which has been widely used to study volunteering intentions, the attitudes (next to subjective norms and perceived behavioural control) are the major antecedents of social engagement (see e.g. Hyde \& Knowles, 2013). Both the 'attitudes' and 'volunteer motivations' are the concepts related to the functional approach therefore the question of their theoretical overlap arises. In one of the few studies where these concepts are combined within one model, Brayley et al. (2015) claim that the volunteer motivations 'may represent deeper psychological constructs that are theoretically distinct from the standard attitudes (...), which typically assess (...) perceptions of the instrumental and experiential benefits or disadvantages of performing a behaviour (Brayley et al., 2015, pp. 150-151). This statement points at the subtle difference between attitudes towards volunteering and volunteer motivations. The former term is only an opinion about potential rewards from volunteering. The positive attitude can be translated into action only if the need corresponding to a particular volunteering function remains unsatisfied.

\section{Volunteer motivations and personality traits}

A prosocial personality is defined as 'an enduring tendency to think about the welfare and rights of other people, to feel concern and empathy for them, and to act in a way that benefits them' (Penner \& Finkelstein, 1998, p. 526). Prosocial personality is considered a dispositional aspect of one's social involvement developed in early childhood. The most popular conceptualization of this term recognizes two dimensions - helpfulness and other-oriented empathy. The first element reflects one's propensity to provide help. The second dimension represents 'the tendency to experience empathy for and to feel responsibility and concern about the well-being of others' (Penner \& Finkelstein, 1998, p. 526). The seminal model of social engagement by Omoto and Snyder (1995) treats motivations and prosocial personality as distinct constructs. The analysis of correlations between variables used in their model supports this assumption with the exception of a value-expressive function of volunteering, which is highly correlated with all measures of prosocial personality (Omoto \& Snyder, 1995, p. 678). Therefore, it seems that a prosocial personality implies a value-expressive motivation (volunteer functions are associated with particular needs and a value-expressive need cannot be experienced by individuals characterized by low scores on prosocial personality).

\section{Volunteer motivations and social support}

The social function of volunteering can be potentially confused with the social support for voluntary engagement. The social function of volunteering 'may offer opportunities to be with one's friends or to engage in an activity viewed favourably by important others' (Clary et al., 1998, p. 1518). The social support is often included in models explaining 
voluntary engagement as a non-psychological variable characterizing the social network of an individual. The items measuring respectively a social function of volunteering (e.g. 'people I am close to want me to volunteer') and social support (e.g. 'people who are important to me support my volunteer work') may seem similar, however, they emphasize a subtle difference between two terms in question (Clary et al., 1998, p. 1520). The first item is related to a specific need to 'behave in socially desired ways' (Clary et al., 1992, p. 338) while the latter represents the support (or lack of it) of one's voluntary work regardless of the motivation driving this activity.

\section{Volunteer motivations and obligations}

Omoto and Snyder (1995) define obligation as a recipient-helper relationship established and strengthened by legal, familial or ethical forces. In this way authors differentiate between care delivered by family members and by volunteers. The latter type of caregiving is referred to as 'helping without obligation' (Omoto \& Snyder, 1995, p. 671). The authors, however, do not elaborate on ethical sources of obligation, which seem to be closely related to a value-expressive function (the sample item describing it in the VFI: 'I feel it is important to help others' or to a protective function ('doing volunteer work relieves me of guilt over being more fortunate than others'). The existence of the ethical obligation is strongly associated with the unmet need of an individual (otherwise the feeling of obligation would be absent) therefore we claim that 'obligation' falls into the category of a volunteer function (value-expressive or protective).

\section{Volunteer motivations and values}

According to Schwartz values are beliefs that pertain to desirable end states or behaviours (Schwartz, 1992, p. 4). In this framework values express basic human needs as well as motivational goals (Hitlin \& Piliavin, 2004, p. 380) and therefore are conceptually close to motives defined in the functional framework.

The functional approach makes these two terms distinct through the introduction of a value-expressive function of volunteering. Particular values important to an individual can but do not have to be expressed through social engagement. It depends on individual needs. Interestingly, in the functional approach only a prosocial value type can be expressed through social engagement. The theory developed by Schwartz (1992) recognizes many more types of values: self-direction (described by such characteristics as freedom or creativity), stimulation (exciting and varied life), hedonism (enjoying life), achievement (being influential or capable), power (authority, social recognition) security (social order, reciprocation of favours), conformity (obedience, politeness), respect for tradition, spirituality (harmony, meaning of life), benevolence (being helpful, responsible, forgiving), and universalism ${ }^{4}$ (equality, social justice, environmental protection). It seems

\footnotetext{
4 Prosocial value gave rise to benevolence and universalism.
} 
that some of these values could also be expressed through volunteering while some are conceptually close to other volunteer functions, such as stimulation to understanding, hedonism to career, and enhancement to power.

The abovementioned inconsistencies indicate that the relationship between values and volunteer motivations is not clearly defined. However, there are at least two significant differences between these two concepts. First, unlike motivations or needs, values are independent of the context. Second, individuals are more frequently aware of the values important to them, whereas motivations often remain unconscious (Arieli et al., 2014, p. 14).

\section{Research methodology}

Qualitative data

The data used in this analysis come from the original survey which consisted of a quantitative and a qualitative component. In the quantitative part a random sample of NGOs was contacted and requested to facilitate contact with volunteers cooperating with them. The volunteers were asked to complete an online questionnaire containing the VFI and a battery of questions concerning the nature of their voluntary work as well as socio-economic characteristics. The results of the quantitative analysis has been presented elsewhere (Buttler, 2018). Respondents were also asked for consent for participation in the in-depth interviews.

Finally, 26 respondents from all over Poland and diversified in terms of the economic and familial status, age, place of residence and length of volunteering took part in the semi-structured interviews. The selected respondents' characteristics are presented in Table 1.

The questions concerned all six types of volunteer motivations identified in the functional approach (practical examples of such motivations as well as some VFI items were provided to increase the respondents' understanding). The participants responded by declaring how important these motivations were in their voluntary work. They were also asked to describe circumstances in which they started their engagement, their responsibilities as volunteers as well as advantages and disadvantages of their social involvement. The survey took place in 2016. The interviews were conducted face to face by five experienced researchers (mostly $\mathrm{PhD}$ students in sociology). The content was recorded and fully transcribed. All the quotations used in the empirical part of the paper have been translated by the author as well as anonymized. The ID numbers of interviewees are provided both in Table 1 and in brackets following the quotations. 
Table 1. Selected characteristics of respondents

\begin{tabular}{|c|l|c|l|l|}
\hline No. & \multicolumn{1}{|c|}{ ID } & age & \multicolumn{1}{|c|}{ sex } & \multicolumn{1}{|c|}{ city size } \\
\hline 1 & 661 & 23 & male & $>100 \mathrm{k}$ \\
\hline 2 & 4655 & 18 & male & Warsaw \\
\hline 3 & 6467 & 62 & male & $10-100 \mathrm{k}$ \\
\hline 4 & 105590 & 36 & female & $>100 \mathrm{k}$ \\
\hline 5 & 127759 & 23 & male & $>100 \mathrm{k}$ \\
\hline 6 & 184179 & 56 & male & $10-100 \mathrm{k}$ \\
\hline 7 & 185126 & 47 & male & $<10 \mathrm{k}$ \\
\hline 8 & 188057 & 49 & male & $<10 \mathrm{k}$ \\
\hline 9 & 193038 & 57 & male & $>100 \mathrm{k}$ \\
\hline 10 & 230790 & 52 & male & $<10 \mathrm{k}$ \\
\hline 11 & 231176 & 40 & female & $<10 \mathrm{k}$ \\
\hline 12 & 234509 & 36 & male & Warsaw \\
\hline 13 & 234667 & 26 & female & Warsaw \\
\hline 14 & 236230 & 34 & female & $<10 \mathrm{k}$ \\
\hline 15 & 236323 & 22 & female & $>100 \mathrm{k}$ \\
\hline 16 & 236352 & 49 & male & $>100 \mathrm{k}$ \\
\hline 17 & 94056 & 69 & male & $10-100 \mathrm{k}$ \\
\hline 18 & 137462 & 43 & female & $>100 \mathrm{k}$ \\
\hline 19 & 145799 & 28 & female & $>100 \mathrm{k}$ \\
\hline 20 & 175095 & 56 & male & $10-100 \mathrm{k}$ \\
\hline 21 & 209825 & 59 & female & Warsaw \\
\hline 22 & 231215 & 36 & female & $10-100 \mathrm{k}$ \\
\hline 23 & 234800 & 69 & male & Warsaw \\
\hline 24 & 236045 & 58 & female & $>100 \mathrm{k}$ \\
\hline 25 & 236068 & 45 & female & $<10 \mathrm{k}$ \\
\hline 26 & 236084 & 48 & female & $10-100 \mathrm{k}$ \\
\hline
\end{tabular}

Source: own elaboration. 


\section{Analytical methods and research aims}

According to Braun and Clarke (2006) the qualitative analytic methods can be divided into two groups. The first one comprises methods like phenomenological analysis, conversation analysis, grounded theory, discourse analysis or narrative analysis, which are strongly associated with a particular theoretical or philosophical framework. A thematic analysis used in this paper represents the second group of methods, which are independent from any particular theory or epistemological position (Braun \& Clarke, 2006, p. 78). It is characterized as a relatively flexible theoretical approach aimed at identifying and analysing theoretical patterns. The thematic analysis is a broad and a vaguely demarcated term therefore it requires transparency with respect to methodological decisions made by researchers. Following the guidelines suggested by Braun and Clarke (2006, pp. 81-86) we make them explicit prior to the analysis. First, we perform a 'theoretical' thematic analysis (in contrast to the inductive approach), which is embedded in a particular conceptual framework (in the functional approach to volunteer motivations in particular). Second, we analyse the data at the directly observable semantic level. However, in some cases, we try to identify the latent ideas and assumptions, particularly, when we search for new types of motivations. In this context the functionalist approach again is the main reference point. Third, our analysis is essentialist/realist in the sense that we directly extract the meaning from interviewees' statements (as opposed to the constructivist perspective assuming that the meaning is socially constructed). Fourth, the main themes of the analysis are the volunteer motivations defined in the functionalist spirit.

The qualitative analysis was performed using ATLAS.ti 9 software. All 26 interviews were coded twice. As a result, the original list of 134 codes indicating volunteer motivations and related terms discussed in the previous section (personality traits, attitudes, obligation, social support and values) was reduced to 74 where 38 concerned various aspects of 8 distinct volunteer functions (6 identified by the original typology and 2 new ones). The codes were attached to quotations representing them.

\section{Motivations of volunteers. The results of the qualitative analysis}

\section{Social function}

The original framework distinguishes two important aspects of the social function, an opportunity to impress or satisfy significant others and an opportunity to interact with a desirable social group (Clary et al., 1998, p. 1518). In many interviews the first aspect was associated with a figure of a 'patron' who gained his/her status of a 'significant other' through his/her superior position over an individual (a parent or a relative, a teacher, a superior), or recognition in the local community (a parish priest, a public officer) or admirable characteristics (a successful local activist). Depending on specific reasons the patron became the 'significant other', her/his influence was either an inspiration or resulted from some forms of pressure. This is illustrated in the following extracts: 
[A lecturer] announced that her organization was looking for volunteers (...) At first I refused (...) I said perhaps after holidays (...) She asked again in October (...) Finally it was awkward to refuse again so I agreed. [236323]

They [a couple of activists] moved in a dilapidated school building to live together with the 'dregs of society' [whilst] having little children and expecting another one (...) They chose this form of aid instead of [psychiatric] drug stuffing (...) a great respect. Someday I'd like to achieve at least half of what they have done. [661]

Also a deceased person can become the patron which also confirms that the social function of volunteering can occur when there are no forms of direct pressure:

He was a parson in our parish but also a scientist. A week after he died we established an association (...) since the priest was a keen activist [236352].

The second aspect of the social function usually emerged in the context of dense social networks of friends, peers or colleagues serving as reservoirs of potential volunteers, e.g. among scouts, (university) students, teachers, or officers. In such groups the social function manifested itself as a consequence of a direct request from a member of a social group. Such a person usually cannot exert pressure or inspire, unlike the patrons. They rather serve as a source of information and encouragement:

My friend (...) was active in one of those organizations. He said: come and give it a try, our people are nice, we need help, you can speak English and we need someone like you. [105590]

Influence of the family was frequently mentioned in the context of the social function of volunteering. This type of influence is complex since parents or relatives, through the process of upbringing, shape prosocial personality (association with the valueexpressive function). They are usually able to put pressure on their children and their own involvement and achievements inspire for action. Family can also act as a source of information about volunteering opportunities.

The analysed interviews revealed two other important aspects associated with the social function. First, many respondents admitted that thanks to volunteering they could meet new friends. Interestingly, this aspect was originally recognized in the VFI as a part of the enhancement function. However, it turned out to correlate strongly with the understanding function (Clary et al., 1998, p. 1520). It can be justified theoretically since that function recognizes the value of new experiences and variety in life. A similar, however distinct motivational facet was related to the opportunities to interact with people sharing similar interests, systems of values, etc. It emphasised the joy of being a part of the community, friendship, or doing something important together. This facet was recognized as a distinct type of motivation by Esmond and Dunlop (2004). We also treat it as a separate construct and will discuss it in the next section. 


\section{Protective function}

The protective motive for volunteering stems from the ego-defensive function recognized by Katz (1960). It 'allows people to avoid acknowledging unpleasant aspects of self or of the external world' (Carpenter et al., 2013, p. 210). In the VFI these unpleasant aspects concern personal problems including loneliness and guilt over being more fortunate than others. The first facet was present much more frequently in the interviews, however, interviewees rarely mentioned serious personal problems (unsuccessful professional life, divorce, or a chronic disease of a close relative). The protective function of volunteering usually manifested itself as an opportunity to escape from difficult, boring or undervalued everyday activities:

I generally run away (...) I guess these are two completely different worlds. Here [in the professional work context] I have to deal with (...) huge problems, and we have to make very serious decisions. Here [in the volunteering context], I do something completely different. I study, talk, and discuss things. It is even a form of release [6467].

The second aspect was also mentioned, however, it rarely concerned the feeling of guilt per se but rather was a form of obligation towards those less fortunate:

I did some volunteering earlier (...) it involved cleaning up a Jewish cemetery (...) maybe it was not the feeling of guilt but (...) of a certain obligation towards the deceased Jews. [231176]

Some interviewees declared that the obligation was very often governed by the norm of reciprocity, which, if unfulfilled, could trigger the feeling of guilt. The following extracts exemplify various versions of the norm of reciprocity:

If someone was lucky enough to be born in an environment free of dysfunctions or problems (...) it is the elementary social and civic duty (...) to help those who were deprived of opportunities. [127759]

I received a scholarship funded by the Capital City of Warsaw [to study]. In a way, I felt responsible for paying back and working off everything that I had received. [4655]

The frequent mentions of obligation in the context of the protective function cast doubts on the suggestions formulated by Esmond and Dunlop (2004) or Hochstetler (2013) to perceive it as a separate motive for volunteering.

\section{Enhancement function}

According to Clary et al. (1998) the negative and positive aspects of an ego-defensive function identified by Katz (1960) should be treated as separate constructs rather than the extreme endpoints of the same scale. Therefore, next to the protective function of volunteering, they also identified a positive aspect of ego-related motivations. It is represented by the enhancement function of volunteering which: 'involves a motivational 
process that centers on the ego's growth and development' (Clary et al., 1998, p. 1518). A person driven by the enhancement motive 'already feels good about him — or herself but volunteers for the purpose of feeling even better' (Clary et al., 1992, p. 338). The enhancement function is associated with the feeling of being needed or important, which results in increased self-esteem.

In the analysed interviews, the enhancement motive was the most frequently mentioned volunteer function covering a broad variety of aspects. The most important context in which the enhancement function was mentioned concerned the effects of voluntary work. Interestingly, a vast majority of volunteers could easily identify or even quantify these effects:

I definitely had this feeling [of doing something important] when we organised the curling weekend [a sport event] and saw that people were genuinely interested in it (...) a person that came alone on Saturday (...) came back with five friends on Sunday. [145779]

I am aware of the value of the organization that I manage; it has undoubtedly contributed to the history of this city, and has done a great job as 130 publications and almost 550 lectures (...) is quite an achievement (...) and only a few people can be proud of having earned it. [6467]

The list of various effects is long and diverse, including instances of a new football pitch, a sport hall, a road, a canoe trail, a high position of a student in a competition, new skills acquired by pupils, large audience at a concert, happy children at a charity event, or a postponement of death penalty. Most of the effects can be classified into two groups. The first one is associated with contribution to shaping other people (teaching new skills or conveying particular values) while the other, with creating something new that would be impossible without the voluntary engagement. The analysis of co-occurrence of codes indicated that the description of the effects was frequently accompanied by a picture of high self-esteem (satisfaction, the feeling of being needed or of doing something important).

Social recognition was another important aspect mentioned in the context of the enhancement function. Respondents identified its various forms, including expressions of appreciation, mentions in the newspaper or other publications, diplomas or medals. However, as the following extract suggests, social recognition was not necessary to experience the feeling of satisfaction from the effects of voluntary work:

I dress up as cartoon characters [to cheer up children who stay in the hospital]. They don't know it's me. I find it satisfying when these children are happy that Mickey Mouse or Winnie the Pooh has come to visit them (...) They ignore the fact that I am a man in disguise, and are happy to see a particular character. [234667]

In many interviews the description of the effects described in the positive context was contrasted with the tedious, tiresome, and sometimes boring process of achieving it. This was often associated with a particular form of obligation. 
All these current activities are rather boring, and (...) due to the increased bureaucracy (...) it's even a bit annoying, however (...) I'm doing it now [because] I know the club could collapse if I quit. [193038]

Some authors treat this form of obligation as a new function of volunteering. For example, Hochstetler (2013) justifies it referring to the concept of a psychological contract which obliges volunteers to persist in their roles. The extract mentioned above suggests, however, that such incentive is not related to any particular unmet need, which is a defining category for the volunteer function. It is also clear that unlike other functions, this kind of obligation can explain why volunteers persist in their work, but not why they have become involved in the engagement. Finally, some extracts suggest that the obligation is linked to the enhancement function. The respondent quoted above, when asked to elaborate on his motivation for voluntary work, provided the following answer:

This voluntary work is needed to ensure that this [sport] discipline stays in our voivodeship, in our county (...), and in our school, and is perceived as important and significant, and that people know of this club (...). [193038]

This extract clearly refers to the categories defining the enhancement motive (feeling needed or important).

\section{Career and understanding functions}

In the quantitative analyses of volunteer motivations, 'career' consequently is the least important function. It is relatively meaningful for younger volunteers who do not have established professional careers. The analysed interviews confirmed this pattern. Most respondents found career perspectives as an insignificant motivation for their engagement. Some admitted that volunteering fostered their professional development (gaining new skills or business contacts). It was, however, an unintended and unexpected effect of their engagement therefore could not be treated as a motivation. Students were the only group in which the career function had some relevance (gaining new skills and development of curriculum vitae). In one case the unmet career motivation led to quitting a voluntary job:

I resigned because I felt (...) that management [of an elementary school] were not actually looking for a person who would support the children, but for a policeman guarding order during lessons, and whose job would be (...) to make sure that they did not throw rubbish at the teacher. [236323]

The analysis of interviews confirmed the understanding function as an important motivation for volunteering. In general, all the aspects of that function (learning about a cause, gaining a new perspective, discovering own strengths, or learning new things including the ability to deal with a variety of people) were easily indefinable in the analysed text. In many instances it was hard to differentiate which specific aspect the respondents referred to. The following extract exemplifies it: 
I was considering a specialization in psycho-oncology. It was important. Therefore, I was looking for something [i.e. voluntary work] that would actually confirm that this was (...) a good idea (...) When you come to an oncology department, you get to know yourself (...) if you see, for example, a child (...) who is more irritable on a given day (...) A child undergoing chemotherapy has the right to be irritated, doesn't it? [234509]

This short extract practically fits all aspects of the understanding function and suggests that this motive for volunteering is a cohesive and a well-defined construct.

Respondents could easily identify a broad range of competences acquired through voluntary work, including managerial skills (motivating others, delegating responsibilities, or decision taking), professional skills (accounting, computer programming) and soft skills (dealing with people, negotiating, communication, time management, or solving problems). However, in many cases we were unable to determine whether personal development was an underlying motive for social engagement or whether it was rather an unexpected effect of engagement, as in the case of career function.

\section{Values function}

The quantitative analyses using the VFI suggest that the value-expressive function is the most important motive for voluntary work. The original framework developed by Katz (1960) does not specify which values are expressed through attitudes. Yet the functional approach to volunteer motivations mostly recognizes the prosocial value (concern for other people, particularly those in need, or the feeling of compassion). Only one item in the VFI is open to other values, but its content its rather vague (doing something for a cause that is important to me). In the analysed interviews it was possible to identify a broader variety of values, including those identified by Schwarz (see section 'Volunteer motivations and values'). Below we present the extracts exemplifying such values as:

\section{Universalism and benevolence}

The campaign about (...) refugees from Syria. It was simply to attract attention to this problem (...) [to show] that also in Poland there are people who care about it (...) I saw that the sea was throwing dead children onto the beach, and it was horrible for me. [4655]

Security

I worked for many years in the police, where we had to deal with many interventions (...) women were repeatedly intimidated and beaten by men. A girl, who will learn some wrestling, will manage (...) to push this drunk man away (...) to run away. [185126]

Spirituality

I cannot forget this picture (...), which is characteristic for southern countries, where the surroundings are aesthetic, so (...) I started wondering if something [similar] could be achieved in such a small town. [230790]

Achievement and power

you are alone in wrestling (...) your opponent will take advantage of every mistake (...)shortage of skills (...) absence from training (...) the same is in life, if you don't fight for yourself, don't count on someone to fight for you. We teach according to this maxim, fight for yourself. [185126] 


\section{Tradition}

I feel a need to share my knowledge (...) history [of Poland during WW2] should be fairly conveyed so that (...) young people can experience this history, (...) touch it (...), and not just read about it. [188057]

The abundance of various value types raises the question why only the prosocial value is highlighted in the $\mathrm{VFI}^{5}$. Two potential answers emerge. First, a seminal paper in which a VFI was tested concerned a sample of volunteers taking care of AIDS patients (Omoto and Snyder, 1995). In this specific group the prosocial values were probably of central importance. Second, the conceptualization of values by Schwarz and the VFI inventory were developed almost at the same time hence a broader set of values could not be taken into account in the functional approach to volunteering.

\section{New volunteer functions}

\section{Utilitarian function}

As discussed above, all types of motivations for volunteering were derived from the functional approach to attitudes. The relationships between functions representing these two conceptual frameworks are clear with the exception of the utilitarian function. In the classic functional theorizing on attitudes the "utilitarian function serves to help people to maximize utility' and allows to 'distinguish objects that bring pleasure and objects that produce pain' (Carpenter et al., 2013, p. 209). It is obvious, that the career function of volunteering, derived from the utilitarian function of attitudes, concerns only a narrow part of it.

In the analysed interviews a career motive for volunteering emerged rarely or was explicitly assessed as irrelevant. On the other hand, many interviewees emphasized that the activity made them happy or enriched their lives. Both descriptions refer to the concept of subjective well-being, the former to its hedonic definition (living a satisfactory and pleasant life) and the latter to its eudaimonic interpretation (living a life in pursuit of human excellence). These two 'versions' of well-being are illustrated in the following extracts:

There are people who love watching matches. I do not judge it (...) I spend this time at home sitting in front of my computer (...) I am talking with sponsors, and people from all over Poland, from all over the world (...) it gives me great satisfaction if I manage to arrange something (...) I follow the rule that I have to do something every day. I can't afford to waste any day. [184179]

Because I like it (...) it gives me satisfaction (...) as simple as that. That's all. I like it and I would even say that I love it. This kind of work makes me very happy (...). That's why I do it. [236230]

5 It has also caused some practical issues. An interviewed animal rights activist was unable to answer a battery of VFI questions assessing the value-expressive function since some items directly referred to humans (e.g. I feel compassion toward people in need). 
At least two other aspects of the utilitarian function emerge from the interviews. The first one is associated with the concept of passion defined as 'a strong inclination or desire toward a self-defining activity that one likes' (Philippe et al., 2009, p. 4). There is a strong empirical evidence confirming that a harmonious passion 6 increases significantly both hedonic and eudaimonic well-being (Schellenberg et al., 2019). The analysed interviews provide numerous examples presenting volunteering as a pursuit of passion:

I love teaching, maybe I should be a [sport] teacher because I am ever so happy when a child learns forward or backward roll. [185126]

In some cases formal volunteering seems to be the most natural way to practice a hobby:

It turned out that if we really wanted to play [curling], we had to somehow formalize our status, otherwise it was not possible that people interested in the game could just enter the track and start playing. There had to be a club. [145779]

The relationship between the pursuit of passion and well-being can be explained with the use of the concept of flow (Csikzentmihaly, 1990). This term can be defined as a state of deep concentration on a given activity leading to the complete immersion in it. While experiencing the flow 'people typically feel strong, alert, in effortless control, unselfconscious, and at the peak of their abilities. Both a sense of time and emotional problems seem to disappear' (Csikzentmihaly, 1990, p. 1). That state was described by many interviewees as in the case of the respondent whose voluntary involvement originated from studying genealogy of his family:

There was a force that pulled me, an attraction to learn something (...) that was the beginning, when I really got the bug for it (...) I was staying up late to search Internet for at least one mention (...) about my grandfather. [188057]

\section{Social interaction function}

The second aspect of the utilitarian motive could also be considered as a separate function. In the interviews the descriptions of joy or happiness from belonging to the community was often explicitly identified as a motivating factor:

We are never alone [as volunteers]. There are other people who also contribute, who (...) think in a similar way (...) [they] somehow become close to us at some point. (...) I have made many friends, for example (...) it is also a motivation. [234667]

The social interaction motive for volunteering should be defined precisely since it is closely related to other functions. The social function emphasises the normative influence

6 This type of passion is under one's control, contrary to the obsessive passion whose contribution to well-being is not so clear. 
of persons belonging to the network of an individual. The understanding motive stresses the role of learning new things, including getting to know new people. Social recognition is an important aspect of the enhancement function, and it occurs through social ties. A newly recognized social interaction function refers to the need for spending time in a friendly environment. The following extracts show various facets of this motive. The first one relates to the utilitarian function and exemplifies the satisfaction derived from spending time with people who share the same interests or passions:

We have many [interesting] people here (...) and we have always something to talk about. We have amazing enthusiasts here (...) there are many incredibly talented people (...) who are very valuable and can contribute a lot. [6467]

Another aspect refers to the joy of belonging to the community, which is bound together by common experience:

when (...) it [an event organized by the respondent] turns out to be successful (...) and comes to the end (...) There is a nice atmosphere, we have laid-back conversations (...) as if we had just passed an important exam (...) The best moments are when we manage to work together (...) there is time to talk and relax, we simply enjoy spending time together in this nice atmosphere. [145779]

The function of social integration manifests itself also by involving other people in volunteering. It usually concerns family members or close friends. This may result from the concern to strengthen relationship with the loved ones or the desire to share their passions.

I got my wife as well as our children involved in this [activity] (...) maybe it was also the desire to unite the family. My brother-in-law works in IT sector and he maintains our website. [185126]

\section{Conclusions}

In this paper we qualitatively analysed the motivations of volunteers in Poland. The functional approach to volunteering identifying six main motives for social engagement provided the theoretical foundation for this analysis. In the stories reported by the interviewees we were able to identify all types of motivations. However, the analysis of in-depth interviews allowed to capture a wide range of various aspects through which those motivations emerged.

The social function was associated with a figure of a patron - a significant other inspiring or directly urging for voluntary engagement. The status of the 'significant other' was a result of the superior position over an individual, recognition in the local community or admirable characteristics. The other type of manifestation of a social function occurred through social ties: - individuals were simply asked or encouraged to engage in a voluntary action. The protective function was usually expressed by respondents as an escape from boring, difficult or undervalued everyday activities. That motivation 
was rarely driven by the feeling of guilt as it is suggested in the functional approach, and was rather forced by the norm of reciprocity. The enhancement function was a frequently emerging motive covering a wide range of various aspects. The most important one was associated with the satisfaction with the effects of engagement. That was often accompanied by different forms or social recognition, although that factor was of a lesser importance in the ego-enhancement perspective. The career function had some relevance among young volunteers without established professional careers (a desire to gain new skills or to expand curriculum vitae). All aspects of the understanding function identified by the functional theory (learning about a cause, gaining a new perspective, discovering own strengths, or learning new things including the ability to deal with a variety of people) were easily indefinable in the text suggesting that this motive is a cohesive and a well-defined construct. The value-expressive function confirmed its central importance for voluntary engagement. However, the analysis revealed a broader variety of values than the functional approach suggests. Next to the prosocial value, which is emphasised in the VFI, the interviewees also referred to other types of value such as universalism, benevolence, security, spirituality, achievement, or power and tradition.

The analysis allowed to suggest new types of volunteer motivation. The utilitarian function satisfies the need to increase the eudaimonic (living a life in pursuit of human excellence) or hedonic (living a satisfactory and pleasant life) well-being. It is also related to pursuing your own hobby or passion and being a part of a wider community of people who share similar interests or values. This latter aspect could be identified as a separate social integration function. This construct is distinct form the social function which emphasises the normative influence of the significant others or friends. It is not a part of the understanding function where one aspect recognizes meeting new people as a motivation for volunteering. The social integration motive refers to the need for spending time in a friendly environment of people bound together by common experience, values, or interests.

We are of the opinion that there are two reasons which contribute to the value of the analysis performed in this paper. First, it increases our understanding of volunteer motivations within the functional framework. The research in this field is dominated by quantitative studies focused on the psychometric properties of the VFI tested in various contexts, and even if some new functions are proposed, the relevant qualitative material is often limited. As a result, our perception of motivations to volunteer is driven by 30-40 short items presented in the questionnaires. The qualitative analyses provide a more nuanced picture within a standardized quantitative framework.

Second, besides the identification of new volunteer functions, the qualitative analysis presented in this paper has allowed us to suggest modifications in the original VFI. In particular we suggest:

- with respect to the enhancement function - to consider the role of the effects of voluntary work and social recognition,

- with respect to the enhancement function - to drop the item referring to making new friends and consider it as a part of the understanding function, 
- with respect to the protective function - to refer to the feeling of obligation rather than to the feeling of guilt,

- with respect to the value-expressive function - to decrease the role of the prosocial value and recognize a broader set of value types.

Obviously, validity of these suggestions must be tested quantitatively.

\section{References}

Ajzen, I. (2011). The theory of planned behaviour: Reactions and reflections. Psychology \& Health, 26(9), 1113-1127. https://doi.org/10.1080/08870446.2011.613995

Arieli, S., Grant, A. M., \& Sagiv, L. (2014). Convincing Yourself to Care About Others: An Intervention for Enhancing Benevolence Values. Journal of Personality, 82(1), 15-24. https://doi.org/10.1111/jopy.12029

Braun, V., \& Clarke, V. (2006). Using thematic analysis in psychology. Qualitative Research in Psychology, 3(2), 77-101. https://doi.org/10.1191/1478088706qp063oa

Brayley, N., Obst, P. L., White, K. M., Lewis, I. M., Warburton, J., \& Spencer, N. M. (2015). Examining the predictive value of combining the theory of planned behaviour and the volunteer functions inventory. Australian Journal of Psychology, 67(3), 149-156. https://doi.org/10.1111/ajpy.12078

Buttler, D., (2018). Motywacje Wolontariuszy w Polsce. Polityka Spoteczna, 527(2), 29-36.

Carpenter, C., Boster, F., \& Andrews, K. (2013). Funtional Attitude Theory. In J. P. Dillard \& L. Shen (Eds.), The Sage Handbook of Persuasion (154-175). 2nd ed. Sage Publications Ltd.

Chacón, F., Gutiérrez, G., Sauto, V., Vecina, M. L., \& Pérez, A. (2017). Volunteer Functions Inventory: A systematic review. Psicothema, 29(3), 306-316. https://doi. org/10.7334/psicothema2016.371

Clary, E. G., Snyder, M., Ridge, R. D., Copeland, J., Stukas, A. A., Haugen, J., \& Miene, P. (1998). Understanding and assessing the motivations of volunteers: A functional approach. Journal of Personality and Social Psychology, 74(6), 1516-1530.

Clary, E. Gil, \& Snyder, M. (1991). A functional analysis of altruism and prosocial behavior: The case of volunteerism. In Prosocial behavior (119-148). Sage Publications, Inc.

Clary, E. Gil, Snyder, M., \& Ridge, R. (1992). Volunteers' motivations: A functional strategy for the recruitment, placement, and retention of volunteers. Nonprofit Management and Leadership, 2(4), 333-350. https://doi.org/10.1002/nml.4130020403

Clary, E. Gil, Snyder, M., \& Stukas, A. A. (1996). Volunteers' Motivations: Findings from a National Survey. Nonprofit and Voluntary Sector Quarterly, 25(4), 485-505. https:// doi.org/10.1177/0899764096254006

Csikzentmihaly, M. (1990). Flow: The psychology of optimal experience (Vol. 1990). Harper \& Row New York.

Esmond, J. \& Dunlop, P. (2004). Developing the Volunteer Motivation Inventory to Assess the Underlying Motivation Drives of Volunteers in Western Australia. Lotterywest Social Research Grant. 
Finkelstein, M. A., \& Penner, L. A. (2004). Predicting Organizational Citizenship Behavior: Integrating The Functional and Role Identity Approaches. Social Behavior and Personality: An International Journal, 32(4), 383-398. https://doi.org/10.2224/ sbp.2004.32.4.383

Hitlin, S. \& Piliavin, J. A. (2004). Values: Reviving a Dormant Concept. Annual Review of Sociology, 30(1), 359-393. https://doi.org/10.1146/annurev.soc.30.012703.110640

Hochstetler, J. (2013). Revising the Volunteer Functions Inventory: An Exploratory Study of Additional Functions. Northcentral University.

Hyde, M. K. \& Knowles, S. R. (2013). What predicts Australian university students' intentions to volunteer their time for community service? Australian Journal of Psychology, 65(3), 135-145. https://doi.org/10.1111/ajpy.12014

Katz, D. (1960). The Functional Approach to the Study of Attitudes. Public Opinion Quarterly, 24(2), 163-204. https://doi.org/10.1086/266945

Law, B. M., Shek, D. T., \& Ma, C. M. (2011). Exploration of the factorial structure of the revised personal functions of the volunteerism scale for Chinese adolescents. Social Indicators Research, 100(3), 517-537.

Omoto, A. \& Snyder, M. (1995). Sustained helping without obligation: Motivation, longevity of service, and perceived attitude change among AIDS volunteers. Journal of Personality and Social Psychology, 68(4), 671-686.

Penner, L. A., \& Finkelstein, M. A. (1998). Dispositional and structural determinants of volunteerism. Journal of Personality and Social Psychology, 74(2), 525-537. https://doi. org/10.1037/0022-3514.74.2.525

Penner, L., \& Orom, H. (2010). Enduring Goodness: A Person-by-Situation Perspective on Prosocial Behavior. In M. Mikulincer \& P. Shaver (Eds.), Prosocial motives, emotions, and behavior: The better angels of our nature. (55-72). American Psychological Association.

Philippe, F. L., Vallerand, R. J., \& Lavigne, G. L. (2009). Passion Does Make a Difference in People's Lives: A Look at Well-Being in Passionate and Non-Passionate Individuals. Applied Psychology: Health and Well-Being, 1(1), 3-22. https://doi.org/10.1111/j.17580854.2008.01003.x

Rioux, S. M. \& Penner, L. A. (2001). The causes of organizational citizenship behavior: A motivational analysis. Journal of Applied Psychology, 86(6), 1306-1314. https://doi. org/10.1037/0021-9010.86.6.1306

Schellenberg, B. J. I., Verner-Filion, J., Gaudreau, P., Bailis, D. S., Lafrenière, M.-A. K., \& Vallerand, R. J. (2019). Testing the dualistic model of passion using a novel quadripartite approach: A look at physical and psychological well-being. Journal of Personality, 87(2), 163-180. https://doi.org/10.1111/jopy.12378

Schwartz, S. H. (1992). Universals in the Content and Structure of Values: Theoretical Advances and Empirical Tests in 20 Countries. In M. P. Zanna (Ed.), Advances in Experimental Social Psychology. (Vol. 25, pp. 1-65). Academic Press. https://doi.org/10.1016/ S0065-2601(08)60281-6

Smith, M. B., Bruner, J. S., \& White, R. W. (1956). Opinions and personality. John Wiley \& Sons. 